\title{
Revisão do zoneamento ambiental minerário do município de Tremembé - SP com a utilização de imagem de alta resolução espacial
}

\author{
Benedito Jorge dos Reis ${ }^{1}$ \\ contato@e-consultingltda.com.br \\ Celso de Souza Catelani ${ }^{1}$ \\ cscatelani@gmail.com \\ ${ }^{1}$ E-COnsulting - Consultoria Ambiental \& Tecnologia da Informação Ltda \\ Rodovia Álvaro Barbosa Lima Neto, 2.370- 12120-000 - Tremembé - SP, Brasil
}

\begin{abstract}
The lack of precision observed when working with Raster maps of the Environmental Mining Zone Department of the Environment of the State of Sao Paulo encouraged Reis (2005) to develop a georeferenced database with a digital model of the Environmental Mining Zone for assessment of mining floodplain of the river Paraíba do Sul Using this database by the Municipality of Tremembé raised the need to adjust the zoning to reality Mining and conditions of the city. We developed a new zoning on the scale 1:10,000 georeferenced to the description of the polygon perimeter commencing at 01 (one), located in the projection system georeferenced to UTM Datum SAD-69, Central Meridian $45^{\circ} \mathrm{W}$ of Greenwich, with its coordinates , from which it describes the development perimeter with their points, coordinates, directions and distances, in order to give more credibility and reliability to the actions of licensing and supervision. The results of the review of the new Zoning Mining of Bog were consolidated in Complementary Law No. 184/2008 that established the Participation Master Plan of the City of Tremembé, who devoted a chapter exclusively for Macro-area of Mining. This chapter, in Articles 20 to 26, incorporates in the form of law, all concepts and rules to be followed for the extraction of sand in the town of Tremembé.
\end{abstract}

Palavras-chave: zoneamento minerário, banco de dados georreferenciado, areia.

\section{Introdução}

Em 1996, a Secretaria do Meio Ambiente do Estado de São Paulo (SMA/SP) deu início à execução da consolidação de normas técnicas e procedimentos de licenciamento ambiental; gerando o Zoneamento Ambiental da Mineração de Areia e o desenvolvimento de uma metodologia de fiscalização e licenciamento, buscando formas de agilizar os procedimentos de licenciamento e recuperação, tornando mais eficazes as medidas de melhoria da qualidade ambiental, promovendo maior articulação entre o poder público e empreendedores, visando garantir a conservação desta região (SÃO PAULO, 1997).

A escolha da área para o zoneamento minerário foi definida pela verificação dos municípios com maior concentração de empreendimentos de mineração de areia, selecionando-se o trecho entre Jacareí e Pindamonhangaba. Neste trecho, foi executado o levantamento do potencial mineral de areia através de um projeto de pesquisa específico, e ainda a elaboração do mapa de uso do solo, atualização do cadastro dos empreendimentos minerários e levantamento das políticas públicas da região. A definição e a delimitação da faixa de potencial de areia foi baseada no estabelecimento dos limites das construções eminentemente arenosas ou do cinturão meândrico pertencentes ao sistema fluvial meandrante holocênico do rio Paraíba do Sul (RICCOMINI et al., 1996). Os produtos do zoneamento minerário foram impressos em dois volumes: o primeiro se constitui num texto ilustrado e, o segundo, compõe-se de 16 mapas na escala 1:25.000, dos seguintes temas: mapa geológico, mapa dos empreendimentos minerários, mapa de uso institucional e mapa dos títulos minerários.

Os mapas em formato Raster do zoneamento ambiental da mineração de areia produzidos pela SMA/SP através do Instituto Geológico, na escala 1:25.000, tem sido utilizados sistematicamente pelos órgãos ambientais licenciadores e fiscalizadores das atividades minerárias no Estado de São Paulo. 
Visando a avaliação da atividade mineraria de extração de areia pelo processo de cavas submersas, Reis et al (2006) desenvolveu uma base de dados georreferenciada que abrangia o período de 1992 a 2003, que permitiu a integração de informações analógicas e dados orbitais de sensoriamento remoto. Essa base de dados teve como objetivo, ser utilizada no monitoramento da evolução da atividade de mineração com fins de fiscalização do cumprimento da legislação e para orientação de projetos de recuperação das áreas degradadas pela atividade mineraria no Vale do Paraíba.

$\mathrm{Na}$ implementação do banco de dados georreferenciado no sistema de informações geográficas SPRING v.4.3.2 (CÂMARA et al., 1996), foram utilizados dados do sensor Thematic Mapper do satélite Landsat 5 e Enhanced Thematic Mapper do satélite Landsat 7. Para a manipulação e a integração dos dados, o banco de dados georreferenciado permitiu a incorporação de mapas existentes, operações aritméticas diversas e a quantificação da área ocupada pela atividade mineradora de areia no trecho entre os municípios de Jacareí e Pindamonhangaba no médio Vale do Paraíba Paulista para o período de análise.

A Prefeitura Municipal de Tremembé realizou um processo de revisão do zoneamento ambiental minerário dentro dos limites do seu município, com o auxílio do banco de dados georreferenciado desenvolvido por Reis (2005), e com a utilização de imagem de alta resolução do satélite Ikonos II

Os resultados da revisão do novo Zoneamento Minerário de Tremembé foram consolidados na Lei Complementar $n^{\circ} 184 / 2008$ que instituiu o Plano Diretor Participativo do Município de Tremembé, que dedicou um capítulo exclusivo para a Macrozona de Mineração. Esse capítulo, nos seus artigos 20 a 26, incorpora na forma de lei, todos os conceitos e regras a serem seguidas para a extração de areia no município de Tremembé.

Este trabalho demonstra a maturidade do município no exercício da competência de legislar sobre assuntos de interesse local que lhe é atribuída pelo Artigo 30 inciso I da Constituição Federal. Este preceito constitucional concede aos entes locais uma competência legislativa exclusiva nas áreas onde predomine o interesse local. O conceito do "interesse local" ocupa uma posição central para a definição do conteúdo da autonomia municipal no Brasil. A predominância, e não a exclusividade é a justa interpretação desse novo conceito

\section{Material e Métodos}

A área de estudo situa-se na planície aluvial do rio Paraíba do Sul, no município de Tremembé, Vale do Paraíba, entre os municípios de Taubaté e Pindamonhangaba, dentro dos limites do zoneamento ambiental minerário da Secretaria do Meio Ambiente do Estado de São Paulo.

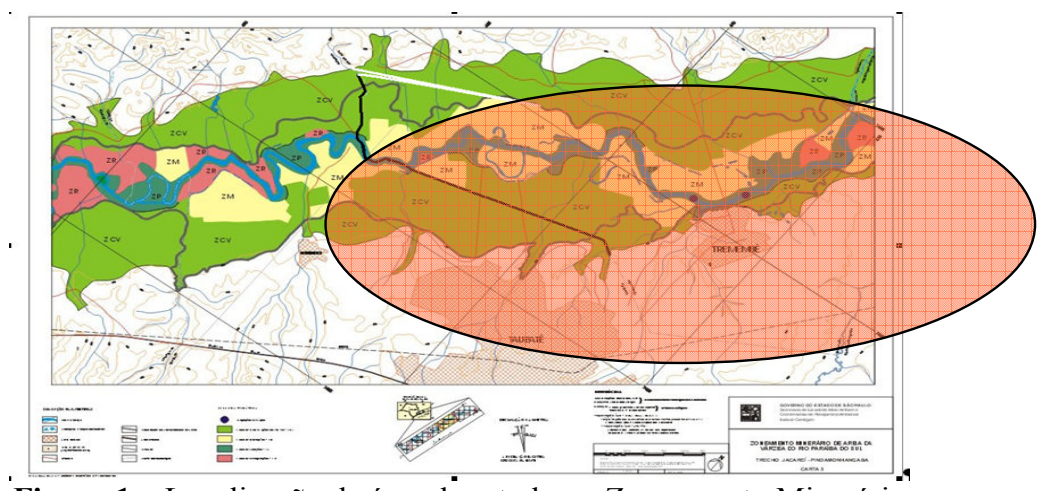

Figura 1 - Localização da área de estudo no Zoneamento Minerário

\section{1 - Refinamento dos dados}


No banco de dados georreferenciado desenvolvido por Reis et al (2006) foi inserida uma composição de imagem de 29 de abril de 2006 do Satélite Ikonos II bandas 1, 2 e 3 (RGB) com a finalidade de se estabelecer um refinamento dos dados obtidos com o sensor Thematic Mapper do Satélite Landsat 5 e Enhanced Thematic Mapper do Satélite Landsat 7. A introdução da imagem do Satélite Ikonos II de abril de 2006 no Banco de Dados Georreferenciado desenvolvido por Reis (2005) possibilitou a ampliação de 900 vezes na resolução espacial permitindo quantificar com maior precisão a área de extração de areia que extrapolava os limites da Zona de Mineração (ZM) do zoneamento ambiental minerário, conforme demonstrado na figura 2 .

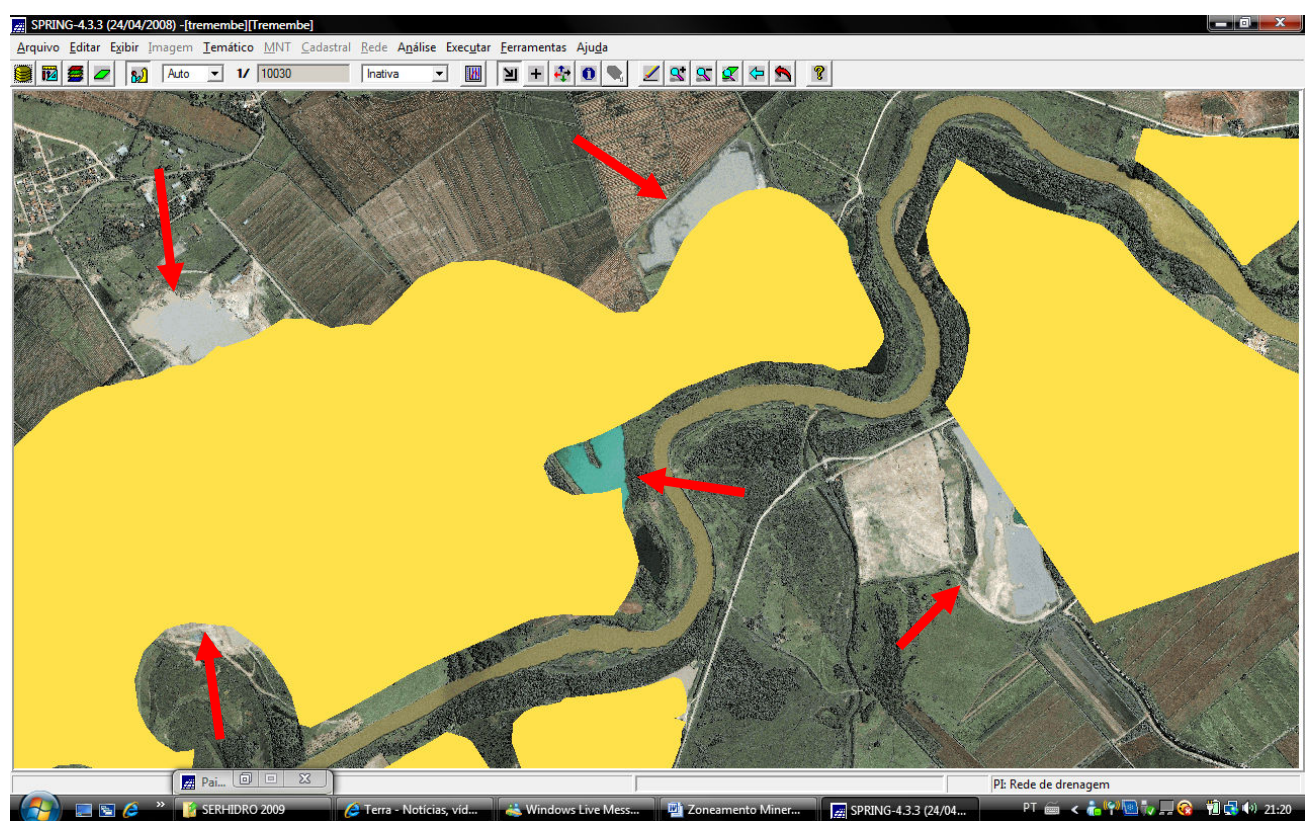

Figura 2 - Vista sobre imagem com setas em vermelho indicando as cavas que extrapolam os limites da Zona de Mineração (ZM) em amarelo.

\section{2 - Levantamento de Dados sobre licenciamento ambiental}

Foi efetuado na Prefeitura Municipal de Tremembé e na CETESB, o levantamento sobre a situação cadastral e regularidade dos portos de areia que possuíam cavas de areia fora dos limites da Zona de Mineração, constatando-se que todos possuíam Licença Ambiental expedida pelos órgãos competentes, achando-se regularizados, porém em desacordo com a Resolução SMA 28/99. Como a exploração já estava consolidada e em alguns casos até encerrada, optou-se pela regularização através de um novo zoneamento com limites georreferenciados e respectivo memorial descritivo do perímetro.

\section{3 - Estabelecimento do pacto pra o novo Zoneamento Minerário}

Foram realizadas diversas reuniões com a participação da Prefeitura Municipal e os detentores de concessão de lavra de areia no município de Tremembé, onde se procurou estabelecer as áreas com elevado potencial de areia fora da área delimitada pela ZM, bem como aquelas dentro do perímetro da ZM que apresentavam baixo potencial para extração de areia.

Tremembé, por ser um dos últimos municípios minerados, haja vista que a exploração iniciada em Jacareí, na década de 90 avançou para Tremembé e Pindamonhangaba (REIS, 
2005), tinha uma Zona de Recuperação (ZR) pequena, em relação à área da Zona de Mineração.

Nessas reuniões com os mineradores, negociou-se a expansão da Zona de Recuperação com áreas já exauridas pela mineração dentro da $\mathrm{ZM}$, estabelecendo-se assim o pacto para $\mathrm{o}$ novo Zonemento Minerário do município de Tremembé.

\section{4 - Desenvolvimento do novo Zoneamento Minerário.}

A partir do Zoneamento Ambiental Minerário produzido pelo Instituto Geológico, no âmbito da Secretaria do Meio Ambiente do Estado de São Paulo, em formato analógico (papel), foi gerada escanerização da folhas, dando origem ao zoneamento minerário em formato raster. Após essa fase, procedeu-se o georreferenciamento da imagem resultante, de forma a incorporar o dado raster ao banco de dados georreferenciado .

Uma vez incorporado o zoneamento minerário ao banco de dados georreferenciado, as linhas que compõem os limites das classes do zoneamento minerário foram vetorizadas, de modo a reproduzir o zoneamento minerário no formato editável dos polígonos.

Com base nos dados georreferenciados e vetorizados incorporados ao SIG - Sistema de Informações Geográficas, procedeu-se então a edição de correção do traçado do zoneamento utilizando como fundo a imagem de alta resolução, que possibilitou a identificação de limites naturais e outros já estabelecidos, tais como margens de rios, estradas, identificação de cercas entre outros.

A melhor resolução das imagens Ikonos II possibilitaram uma melhor identificação das áreas cuja atividade de extração de areia já havia se encerrado, dessa forma, foi possível a indicação de novas áreas a serem incorporadas para ampliação da Zona de Recuperação. Foram observadas ainda a necessidade de um melhor delineamento e correção dos limites da Zona de Proteção e dos limites do leito do rio Paraíba do Sul.

A redefinição dos limites das classes do zoneamento minerário deu origem a um novo conjunto de polígonos, que foram descritos na forma georreferenciada, com a descrição do desenvolvimento dos limites de cada polígono anotado com seu respectivo par de coordenadas UTM, georreferenciados ao Datum Horizontal SAD 69 - Meridiano Central W= $45^{\circ}$ (figura 3 ).

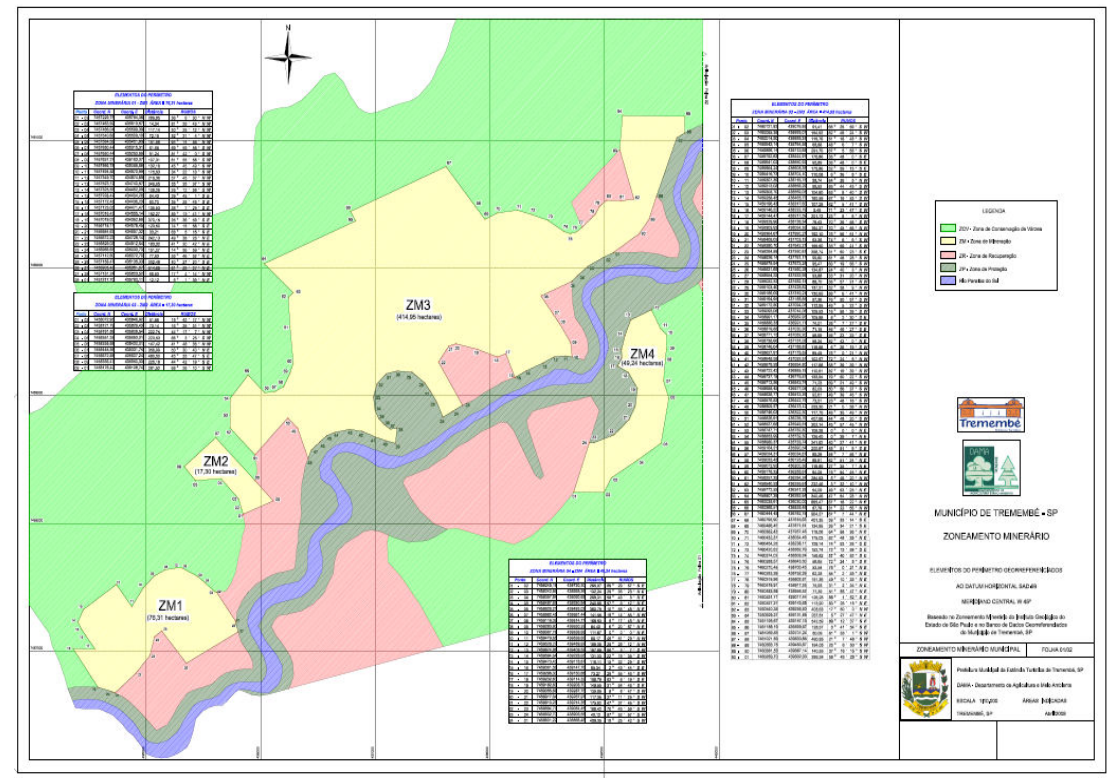

Figura 3 - Novo Zoneamento Minerário georreferenciado e com descrição dos elementos de cada polígono. 
O então novo delineamento do zoneamento minerário, foi incorporado à análise e definição das zonas do plano diretor, o que possibilitou a consolidação do Zoneamento Minerário no Plano diretor Participativo do município de Tremembé.

\section{Resultados e Discussão}

A manipulação do banco de dados através de funções específicas do SPRING resultou na determinação das áreas de cavas existentes nas diversas classes do zoneamento ambiental minerário. Observou-se que entre 1997 e 2003, houve um crescimento da atividade minerária nas Zonas de Preservação, Recuperação e Conservação de Várzea.

A inserção no banco de dados georreferenciado de imagem de alta resolução do satélite Ikonos II de abril de 2006 com cobertura do município de Tremembé possibilitou verificar que naquele município a área de cavas que extrapolava os limites do zoneamento ambiental minerário eram muito maiores do que aquelas verificadas anteriormente com imagens de menor resolução espacial.

O novo Zoneamento Minerário de Tremembé apresentou como produto final um conjunto de 5 mapas e 12 memoriais descritivos, sendo um para cada polígono componente da Zona de Mineração (ZM). A tabela 1 descreve o conteúdo de cada um dos 5 mapas produzidos.

Tabela 1 - Conteúdo do Zoneamento Minerário do Município de Tremembé

\begin{tabular}{|c|l|c|}
\hline FOLHA & \multicolumn{1}{|c|}{ CONTEÚDO } & ESCALA \\
\hline Única & $\begin{array}{l}\text { Zoneamento Minerário do Município de Tremembé com as Zonas } \\
\text { de Mineração (ZM), Zona de Recuperação (ZR), Zona de } \\
\text { Conservação de Várzea (ZCV) e Zona de Proteção (ZP) }\end{array}$ & $1: 25.000$ \\
\hline 01/02a & $\begin{array}{l}\text { Polígonos ZM1, ZM2, ZM3 e ZM4 da Zona de Mineração com } \\
\text { elementos do perímetro georreferenciados ao Datum Horizontal } \\
\text { SAD 69 - Meridiano Central W = 45 }\end{array}$ & $1: 10.000$ \\
\hline $01 / 02 b$ & $\begin{array}{l}\text { Polígonos ZM1, ZM2, ZM3 e ZM4 da Zona de Mineração com } \\
\text { elementos do perímetro georreferenciados ao Datum Horizontal } \\
\text { SAD 69 - Meridiano Central W = 45 e indicação das camadas } \\
\text { compreendidas pela ZP, ZR e ZCV }\end{array}$ & $1: 10.000$ \\
\hline 02/02a & $\begin{array}{l}\text { Polígonos ZM5, ZM6, ZM7, Z8, Z9, Z10, Z11 e ZM12 da Zona de } \\
\text { Mineração com elementos do perímetro georreferenciados ao } \\
\text { Datum Horizontal SAD 69 - Meridiano Central W }=45^{\circ}\end{array}$ & $1: 10.000$ \\
\hline $\begin{array}{l}\text { Polígonos ZM5, ZM6, ZM7, Z8, Z9, Z10, Z11 e ZM12 da Zona de } \\
\text { Mineração com elementos do perímetro georreferenciados ao } \\
\text { Datum Horizontal SAD 69 - Meridiano Central W = 45 e } \\
\text { indicação das camadas compreendidas pela ZP, ZR e ZCV }\end{array}$ & $1: 10.000$ \\
\hline
\end{tabular}

A tabela 2 mostra o quadro comparativo das áreas do Zoneamento Ambiental Minerário da SMA e o novo Zoneamento Minerário do Município de Tremembé.

Tabela 2 - Zoneamento Minerário de Tremembé (Novo X Antigo)

\begin{tabular}{|c|r|r|r|r|}
\hline CLASSE & Antigo (ha) & \multicolumn{1}{c|}{ Novo (ha) } & \multicolumn{1}{c|}{ Dif. (hectares) } & \multicolumn{1}{c|}{ Dif. \% } \\
\hline ZCV & $3.699,8$ & $3.177,4$ & $-522,5$ & $-14,12$ \\
\hline ZM & $1.353,5$ & $1.053,7$ & $-299,8$ & $-22,15$ \\
\hline ZP & 643,2 & 616,5 & $-26,7$ & $-4,16$ \\
\hline ZR & 164,4 & 977,8 & 813,4 & 494,78 \\
\hline
\end{tabular}


Os dados da tabela 2 indicam uma redução de 522,5 hectares na ZCV, que é resultante de dois fatores; primeiro, o avanço licenciado da extração para fora dos limites da ZM, que não fora detectado por falta de um instrumento preciso de fiscalização e segundo, pela readequação dos limites da ZM á topografia local e às bordas das áreas de concessão de lavra contidas nas portarias do DNPM.

A ZM, embora tenha sofrido um acréscimo de áreas em função da readequação, teve sua área reduzida em relação ao zoneamento antigo em função da cessão de 813,4 hectares que foram transformados em Zona de Recuperação (ZR).

A redução de 4,16 hectares na Zona de Proteção ZP é resultado da correção dos limites do Zoneamento antigo e da retirada de uma área de 13,14 hectares da ZP que foi incluída na ZM por possuir alto potencial de mineração onde a revegetação era tecnicamente inviável devido ao afloramento da camada de areia na superfície do solo.

$\mathrm{O}$ novo Zoneamento Minerário de Tremembé constitui um ganho de qualidade e confiabilidade nas ações de licenciamento e fiscalização, uma vez que está georreferenciado e cada um dos 12 polígonos contidos dentro da Zona de Mineração possui seu respectivo memorial com a descrição perimétrica do polígono com início num ponto 01 (um), localizado no sistema de projeção UTM georreferenciado ao Datum SAD-69 e meridiano central de $45^{\circ}$ W Greenwich, com as respectivas coordenadas, a partir do qual se descreve o desenvolvimento perimetral com os respectivos pontos, coordenadas, rumos e distâncias.

\section{Conclusões}

O diferencial tecnológico utilizado neste trabalho foi a aplicação de imagens de alta resolução espacial, para o refinamento de trabalho anteriormente realizado com imagens de satélite de baixa resolução

$\mathrm{O}$ avanço tecnológico do Sensoriamento Remoto otimiza as idas à campo, favorece a atualização nos produtos cartográficos e permite uma visão sinótica do meio. Além disso, caminha para o processo de interpretação de micro-feições. O uso das imagens de alta resolução permite diversos estudos ambientais, em especial aplicação, o delineamento de um novo zoneamento minerário, pois possibilitou a definição de feições com 1,00 $\mathrm{m}$ de resolução espacial.

O novo Zoneamento Minerário de Tremembé tornou-se ferramenta de trabalho da Secretaria Municipal de Agricultura e Meio Ambiente com altíssimo grau de qualidade e confiabilidade.

\section{Referências}

Reis, B. J. Avaliação da expansão da atividade de extração de areia na planície aluvial da bacia hidrográfica do Rio Paraíba do Sul no trecho entre Jacareí e Pindamonhangaba no período de 1993 a 2003. Dissertação (Mestrado em Ciências Ambientais). Universidade de Taubaté. 112 p. 2005.

Reis, B. J.; Batista, G. T.; Targa, M. S.; Catelani, C. S. Desenvolvimento de um banco de dados georreferenciados para avaliação de atividades minerarias na planície aluvial do rio Paraíba do Sul. Revista Biociências. Taubaté, Jan/jun 2006, vol.12, nº.12, p.34-42.

São Paulo (Estado). Secretaria do Meio Ambiente. Instituto Geológico. Projeto Paraíba do Sul Potencialidade de Areia. São Paulo, 1997.

Riccomini, C. et al. Rios e processos aluviais. In: Teixeira, Wilson. [et al] (Org). Decifrando a Terra. São Paulo: Oficina de Textos, 2000. $2^{\mathrm{a}}$ Reimpressão, 2003. p. 191-214. 